\title{
Study of neuromarketing: visual influence with decision making on impulse buying
}

Rifat Januar ${ }^{1}$, Hilman Fauzi ${ }^{\star 2}$, Maya Ariyanti ${ }^{3}$, Faradisya Heris ${ }^{4}$

Faculty of Electrical Engineering, Telkom University, Indonesia ${ }^{1,2,4}$

Faculty of Economics \& Business, Telkom University, Indonesia

\section{Article Info}

\section{Keywords:}

Electroencephalography, Support Vector

Machine, Fast Fourier Transform,

Neuromarketing

\section{Article history:}

Received: September 5, 2021

Accepted: October 29, 2021

Published: November 30, 202

\section{Cite:}

Januar, R., Fauzi, H., Ariyanti, M., \& Heris, F. (2021). Study of Neuromarketing: Visual Influence with Decision Making on Impulse Buying. Kinetik: Game Technology,

Information System, Computer Network,

Computing, Electronics, and Control, 6(4).

https://doi.org/10.22219/kinetik.v6i4.1334

${ }^{*}$ Corresponding author

Hilman Fauzi

E-mail address:

hilmanfauzitsp@telkomuniversity.ac.id

\begin{abstract}
Marketing trends have been increasing in the last few decades. Products need good branding and the right marketing strategy. Various marketing methods have been widely done, and one of them is with the study of neuroscience, especially neuromarketing. Neuromarketing is used to seek the influence of marketing stimuli on consumers and objective data through advances in neurology by utilizing human senses such as restraint, smell, taste, and touch. Measurements of neuromarketing responses to the brain can use electroencephalography signals (EEG). Measurement is done with the visual stimulus of consumers when making decisions. To analyze consumer interests, the majority still using qualitative methods, but it is still considered less effective due to many uncertain factors. In this study, neuromarketing responses were measured to the human brain using (EEG) signal analysis. Data collection was conducted on 11 respondents with a stimulus in the form of different product colors and was affected by changes in light intensity. For pre-processing used bandpass filters to get beta signals in the absence of noise. Then the data will be processed using Fast Fourier Transform (FFT) and energy extraction as characteristic extraction and classification of Support Vector Machines (SVM) in the signal pattern recognition process. The results of testing the best feature combination parameters showed an accuracy value of $72 \%$ with a combination of magnitude and phase features. By using the range of phase feature values obtained an accuracy of $67 \%$ for signal pattern recognition respondents.
\end{abstract}

\section{Introduction}

Given the increasing interest in consumers and the economic competitiveness, the production part must have a good marketing strategy to increase customer satisfaction. The experiential marketing method utilizes the human senses, consisting of vision, touch, olfaction, taste, and auditory [1]. Using visual methods to get information from consumers by looks at a product's brand, shape, and color. The visual method also makes consumers interested when looking at a product because Approximately $25 \%$ of the brain regions are related to vision, leading to impulse buying [2]. We believe that impulse buying can be stimulated by an unanticipated need, a visual stimulus, a promotional campaign, or a decreased cognitive capacity to evaluate the advantages and disadvantages of the purchase [3]. Then various products can detect and fulfill the desires of consumers to make a purchase, followed by an increase in s store's sales and profit [4]. The better companies know about the behavior of their customers, the easier they can engage with them [5].

In previous studies, an analysis of consumer desires and satisfaction has been carried out using a questionnaire with a stimulus of light intensity in illuminating a product by utilizing visuals as a medium for making decisions. This study indicates that the intensity of dark and bright light can increase self-sensation and the length of time consumers are in the store so that consumers have more time to think [6]. Attractive store atmosphere has a positive and significant effect as measured by lighting, layout, visual communication (color), and aroma in the store [7]. The higher brightness will make the environment more lively and comfortable than in a dark place [8].

However, qualitative methods such as questionnaires are still inadequate to analyze and study consumer behavior [9]. Because people's decisions take place outside of conscious awareness or under the influence of factors not recognized, the consumers very often do not want to, or do not know how to, explain their choices [9], [10]. Therefore, the qualitative method is considered less efficient in analyzing consumer behavior, so that in this study, using the combined method. Based on this problem, the marketing party obtains information to increase sales by utilizing neuromarketing by identifying consumer impulse responses. Since the brain is invisible to the naked eye, neuromarketing makes it possible to know more about it [11]. The term neuromarketing is a combination of neuroscience and marketing [12]. Neuromarketing focuses on consumer behavior and decision-making process [13], [14]. By using

Cite: Januar, R., Fauzi, H., Ariyanti, M., \& Heris, F. (2021). Study of Neuromarketing: Visual Influence with Decision Making on Impulse Buying. Kinetik: Game Technology, Information System, Computer Network, Computing, Electronics, and Control, 6(4). https://doi.org/10.22219/kinetik.v6i4.1334 
Electroencephalogram (EEG) in real-time [15]. EEG is a tool to get information that is used in the head to record the electrical activity of human brain waves that focus on the front or frontal lobe where this part is the control center of the brain, overseeing higher-level thinking processes, thinking about problem-solving steps, organizing, and controlling effects of the emotional system [16], [17]. However, the characteristics of the EEG signal from each person are different and change over time, which is influenced by various variables such as emotional, mental, age, activity, health, and attractive responses [15], [18].

To detect impulse buying that focuses on a consumer's decision-making. An analysis is carried out when consumers see a product with various colors with a stimulus of changes in light intensity, such as what impulse responses and brain signal patterns are produced. Several studies have focused on the driving role of marketing, highlighting how impulse buying can result from the store or shelf placement, attractive displays, in-store promotions, and light intensity to make consumers feel comfortable [19]. As consumer reactions and perception of visuals and other cues in the real environment are of interest in marketing strategies, it is hypothesized that visual attention attracts the human gaze behavior, which may positively impact the outcome of subconscious decisions when buying the product [20].

The study was measured by using decision-making stimuli that helped determine FLA (Frontal Lobe Activity). This process will be a device for identifying consumer interest or attention to the product. The system built using FFT, the FFT is one of the most well-known and most applied fast algorithms [21]. In the literature, Support Vector Machine has been widely used on EEG data [22]. SVM uses a kernel function to map input data into higher dimensional space using non-linear methods [23]. Thus, the study presented in this paper aims to develop a methodology for evaluating visual attention by measuring neuromarketing responses to the human brain using electroencephalography (EEG) signal analysis.

\section{Research Method}

This system design is designed to visually analyze consumer brain signals for a product using EEG signals. Then an analysis of the consumer's brain response is carried out when deciding to get a signal pattern of consumer behavior. This system consists of 4 stages, that is Data Retrieval, Pre-Processing, Feature Extraction, Classification. The following scheme of work can be seen in Figure 1.

This study will focus on the block model of the system following the research objectives, namely analyzing the respondent's signal output pattern and measuring the EEG signal profile for impulse buying with a light intensity stimulus. The system model will be carried out in stages. This system begins with data collection, which is applied to respondents to obtain a dataset. After the data retrieval process is complete, it processes the dataset at the preprocessing stage to filter the signal according to the desired needs and reduce the existing noise. In this research, the signal needed is the output signal in the beta wave. Then enter the feature extraction stage by finding the magnitude, phase, energy, and amplitude values as feature values for each respondent, which are obtained from the Fast Fourier Transform process, energy extraction and the filtered signal. The feature extraction results will be classified using the machine learning SVM method to obtain the highest accuracy of the features used and determine the parameters for signal pattern recognition.

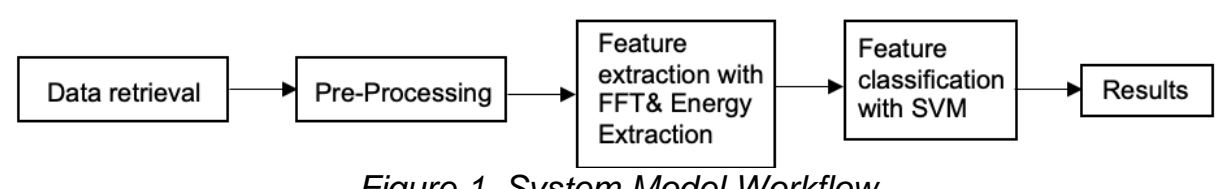

Figure 1. System Model Workflow

\subsection{Data Collection}

In this subchapter, the stage of data collection is carried out on research respondents who act as consumers. All research respondents are students of Telkom University, Faculty of Electrical Engineering, majoring in S1 Telecommunication Engineering with an age range of 21 to 22 years (4 males, 7 females). Before taking respondent data, questions will be asked about the respondent's experience with a color, such as favorite colors and disliked colors. Then the respondent will wear an EEG device neurosky mindwave mobile on his head to analyze brain signals when making decisions. This device is connected to the NeuroExperimenter software and using Lux Meter to measure the light intensity in the room. Then the respondent was shown a plate and glass product with a variety of color choices, and then the respondent was asked to choose one of several existing products.

Respondent data collection was divided into 4 sessions with different light intensities. The respondent is given a stimulus of changes in light intensity which increases in each session, and the EEG will record the response of the respondent's brain in each session. At the end of each session, respondents are invited to choose one of the products with pre-determined colors. Then the same thing is done for each session from session 1 to session 4 . After completing the data collection stage, the respondent can leave the room. Then can compare the results of each session. The

(c) 2021 The Authors. Published by Universitas Muhammadiyah Malang

This is an open access article under the CC BY SA license. (https://creativecommons.org/licenses/by-sa/4.0/) 
division of the retrieval stage in this study is divided into 2, pre-data collection and the data collection process. The following is the division of groups and products used can be seen in Table 1.

Table 1. Research Group

\begin{tabular}{ccccc}
\hline Respondents & Session & Light Intensity & Type of Product & Color Options \\
\hline \multirow{4}{*}{ Men and Women } & 1 & 200 lux & & \\
& 2 & 400 lux & Plates and Glasses & Yellow, Green, \\
& 3 & 600 lux & & \\
\hline & 4 & 800 lux & & \\
\hline
\end{tabular}

During data recording, respondents are provided with a chair with a backrest to be relaxed during the process. Respondents are provided with a computer monitor in front to display the question screen. If it is ready, the respondent is invited to enter and sit on the chair that has been provided for the EEG device to be installed on the respondent's head. Then the EEG device that has been installed on the respondent will be connected to the researcher's laptop using Bluetooth.

The recorded data is displayed on the screen in a graph of the amplitude against time. Data collection consists of 5 parts: pre-session, session 1 , session 2 , session 3 , and session 4 . The timing diagram for data collection can be seen in Figure 2.

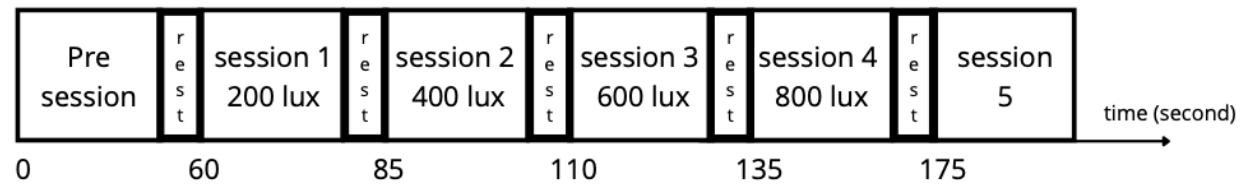

Figure 2. Data Retrieval Time Chart

In pre-session, the activity carried out was the opening followed by notification of the rules for data collection and the steps that must follow from start to finish. Respondents were also asked to see and analyze the products prepared, such as the product's shape or color. In the rest session, the respondents were given time to rest for 10 seconds. The goal is to neutralize the response of the respondent's brain to get maximum results. In sessions, 1 to 4 respondents were asked to choose the product they like with the same time specified for each session, 25 seconds. And also, for each session, the light intensity used will be different, starting from session 1, which is 200 lux, and increasing by 200 lux each session until session 4 reaches 800 lux. Then at the end of each session, respondents were asked to answer what color was chosen by writing on the prepared paper. In the last session, respondents were asked to explain the reasons for choosing the color chosen in each session. There was a difference from session 1 to session 4 that the respondent felt and explained.

\subsection{Pre-Processing}

Pre-processing is a data processing stage that aims to obtain a dataset according to the desired signal profile. By processing data at the scene of collecting data obtained from testing to respondents using a mobile EEG neurosky mindwave device. Because this study will focus on getting respondents' information signals when making decisions, then the signal will be filtered first to remove noise and pass the desired information signal. A beta signal is obtained by using a bandpass filter to give signals with a frequency range of $13 \mathrm{~Hz}$ to $30 \mathrm{~Hz}$. Beta signals are the state of humans when they are aware, focused, and make decisions. Then the information signal obtained will be used for the signal processing dataset in the feature extraction process. This is why pre-processing is one of the most important steps of data analysis in all its forms. Then the information signal obtained will be used for the signal processing dataset in the feature extraction process [24].

\subsection{Feature Extraction}

Feature extraction is the process of taking traits or characteristics of an object to distinguish one object from another. In this study, the Fast Fourier Transform method transforms the EEG signal, which was initially time-based, into a frequency-based EEG signal. The raw EEG signal is a voltage signal over time, and most of the information contained in the EEG signal is in the frequency domain. Therefore, an important process is needed to break down the EEG signal into constituent frequencies such as beta waves which are inputs to find out using SVM [22]. Feature extraction is used FFT to obtain a frequency response that produces magnitude and phase values in the frequency domain. In addition, FFT is also used to determine which frequencies will be filtered using a lowpass, highpass, bandpass, or bandstop filter. Another feature extraction used is energy extraction to obtain the total energy of a particular 

channel and the signal amplitude after being filtered by a bandpass filter. To get the value of power and amplitude used signals in the time domain. The results of the time domain and frequency domain signals can be seen in Figure 3.

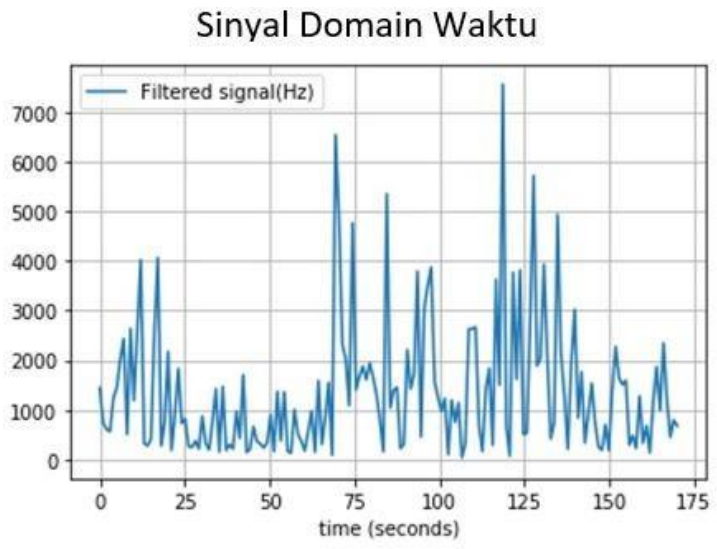

(a)

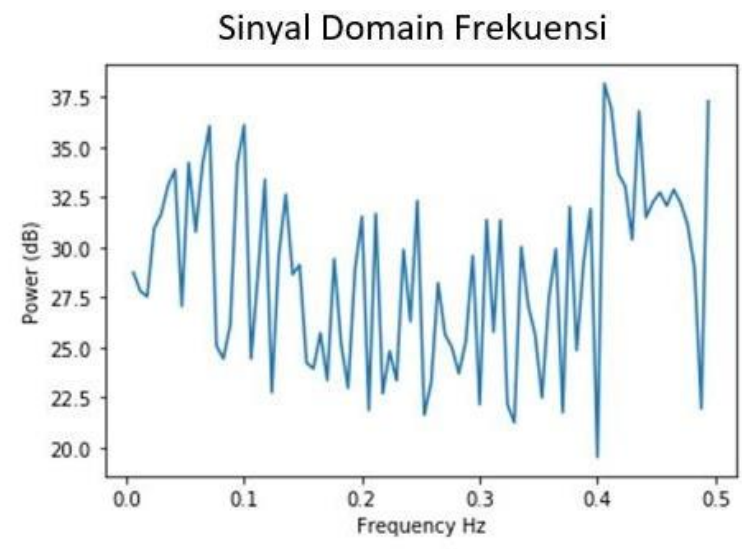

(b)

Figure 3. Signal Pattern. (a) Time Domain (b) Frequency Domain

\subsection{Feature Classification}

The feature classification used in this study is the Support Vector Machines (SVM) method because it has good accuracy and can make predictions quickly. Support vector machine (SVM) has been used widely for the classification of electroencephalogram (EEG) signals [25]. Then for the SVM kernel used is the Gaussian kernel or RBF because the data used is non-linear. Because of this, we cannot use the linear kernel. Then the feature results that had obtained from the session 2 to session 4 dataset will be divided into 15 combined features consisting of a combination of 1 feature to 4 features. After the feature combination dataset for training data and test data has been obtained, the accuracy of the data that has previously been trained by machine learning SVM is sought to predict and classify the test data used.

\subsection{Configuration Parameters}

This sub-chapter will explain the configuration used in this study, starting from the data collection process to classifying features. The following for more details can be seen in Table 2 .

Table 2. Configuration Parameters

\begin{tabular}{cc}
\hline Configuration & Information \\
\hline EG Tools & Neurosky Mindwave Mobile \\
& Frequency of Sampling $128 \mathrm{~Hz}$ \\
Fassing Signals $1-50 \mathrm{~Hz}$ \\
Filter BPF & Passing Signals 13 $-30 \mathrm{~Hz}$ (Beta Signal) \\
Characteristic Extraction & Fast Fourier Transform \& Energy Extraction \\
Support Vector Machine & Kernel RBF (non-linier) \\
Training data & Session 4 (11 Data) \\
Test Data & Session 4 (11 Data) \\
\hline
\end{tabular}

\section{Results and Discussion}

This chapter discusses experimental results and analysis of EEG signals with visual stimuli to obtain accurate results and profile decision-making with the influence of light intensity. Uses a mobile mindwave neurosky EEG device on his head to analyze brain signals while making decisions. With light, intensity makes respondents more interested and influenced. This test consists of three stages. The first stage is to determine the label of each respondent based on the answers at the time of data collection. The second stage is to get the accuracy of the combination of features used to generate condition parameters. The last is to compare and get pattern signals from each respondent.

\subsection{Labeling}

In the first stage, the objective is to determine the label of each respondent by using the respondent's answer sheet as a parameter for determining the label. If the respondent changes his color choice from session 1 to session 4 , it means that the respondent is "affected," and if the respondent does not change his color choice from session 1 to session 4, it means that the respondent is "not affected." 


\subsubsection{Criteria for Determining Label}

The determination of the label is based on the results of the respondents' answers during the data collection process. Respondents can be labeled as affected if they change their color choice in session 1 to another color in sessions 2, 3, or 4 due to changes in light intensity. Then the respondent can be labeled as unaffected if the subject chooses the same color from sessions 1 to 4 , meaning the respondent is not affected by the light intensity. Then the respondent can be labeled as unaffected if the subject chooses the same color from sessions 1 to 4 , meaning the respondent is not affected by the light intensity. Unaffected condition is labeled with the number " 0 ", and the affected condition is labeled with the number "1". In Table 3, you can see an overview of the criteria for defining labels.

Table 3. Label Determination Criteria Table

\begin{tabular}{cccc}
\hline Respondents & Session 2 / 3 / 4 & Condition & Label \\
\hline A & No Change of Choice & Unaffected & 0 \\
B & Changing Options & Affected & 1 \\
\hline
\end{tabular}

\subsubsection{Results and Analysis}

After all, respondents make decisions in each session, where each session has a different light intensity. Starting from 200 (session 1), 400lux (session 2), 600lux (session 3), and 800lux (session 4). Then the selection results are categorized according to the label, label 0 is categorized as an unaffected condition, and label 1 is categorized as an affected condition. Based on the data collection results, it is known that from 11 respondents, 4 respondents were not affected, and 7 respondents were affected. For 4 respondents who are not affected, it is known that they are male and for 7 respondents who are affected are female. Based on the questionnaire results, it is known that respondents who are not affected have a preference for dark colors, such as blue or black. Then for respondents who are affected, it turns out that they have a preference for light colors, such as light blue and pink. As the intensity of light increases, certain colors will become more attractive to some respondents. But in this stage, it is still based on a subjective rather than an objective basis. in Table 4, you can see the response data of all respondents and the label of each respondent.

Table 4. Data Retrieval Table

\begin{tabular}{ccccccc}
\hline Respondents & Gender & $\begin{array}{c}\text { Session 1 } \\
(200 \text { Lux })\end{array}$ & $\begin{array}{c}\text { Session } 2 \\
(400 \text { Lux })\end{array}$ & $\begin{array}{c}\text { Session 3 } \\
(600 \text { lux })\end{array}$ & $\begin{array}{c}\text { Session 4 } \\
(800 \text { lux })\end{array}$ & Label \\
\hline 1 & Men & Blue & Blue & Blue & Blue & 0 \\
2 & Women & Purple & Purple & Yellow & Yellow & 1 \\
3 & Women & Yellow & Blue & Green & Green & 1 \\
4 & Women & Blue & Yellow & Green & Purple & 1 \\
5 & Men & Blue & Blue & Blue & Blue & 0 \\
6 & Women & Blue & Blue & Yellow & Orange & 1 \\
7 & Men & Blue & Blue & Blue & Blue & 0 \\
8 & Women & Blue & Green & Green & Yellow & 1 \\
9 & Women & Green & Blue & Blue & Blue & 1 \\
10 & Women & Yellow & Yellow & Green & Green & 1 \\
11 & Men & Blue & Blue & Blue & Blue & 0 \\
\hline
\end{tabular}

\subsection{Data Parameter}

In the second stage, the aim is to obtain parameter data for determining signal patterns from the combination features with the best accuracy. Then will compare it with the comparison data at the last stage. We use the support vector machine (SVM) classification to get the best accuracy from the 15 combinations of these features. The flow of the experiment in the second stage can be seen in Figure 4.

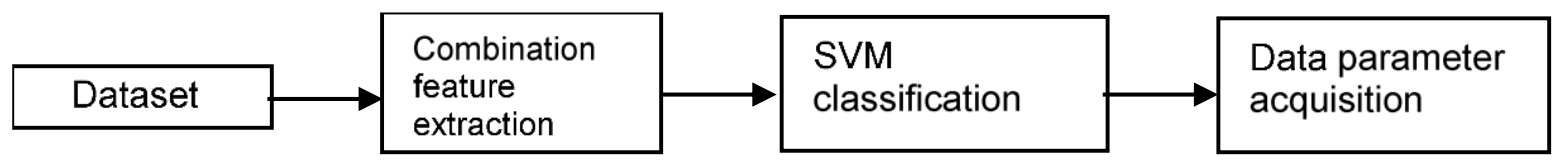

Figure 4. Trial Flow for Parameter Data

\subsubsection{Feature Extraction}

Feature extraction is obtained from the dataset processing using 4 features: magnitude, phase, amplitude, and energy for each respondent. The amplitude value is obtained from the amplitude of the time domain EEG signal after filtering with BPF. All feature values will be averaged, then used as a feature dataset for each session. 


\subsubsection{Test Results and Analysis}

The combination of features used is divided into 4 combination parts, namely the combination of 1 feature, 2 features, 3 features, and 4 features. After that, the accuracy of each feature combination is sought. Based on the accuracy results, it is found that the combination of 2 features using magnitude \& phase and a combination of 3 features of amplitude \& magnitude \& energy has the highest average accuracy of 30 repetitions several 0.72 . Then because there are 2 combinations of features with an accuracy of 0.72 , the standard deviation calculation is used to determine the best results. Then the combination of 2 features of magnitude \& phase has a standard deviation closer to 0 , which is 0.15 . Compared with the standard deviation of the combination of 3 features, amplitude \& magnitude \& energy, it is 0.19 . Based on the accuracy results obtained, it is known that the accuracy value of 0.72 is the highest, and 0.61 is the lowest value. If more data is used and different labeling methods are used, it is possible to get better accuracy results. Then can see that the phase feature has the most significant effect because it produces higher accuracy than other features. This matter can be seen from the results of testing the combination of 1 feature in Table 5 with an accuracy of 0.7 , and also a combination of 2 and 3 features with an accuracy of 0.72 . Based on this, it is known that the phase features tend to be stable, which is around 1.56 to 1.57 . So that it can produce better accuracy, which means the phase has a fairly important role in getting high accuracy and determining the pattern of the respondent's signal. And in the SVM classification, having a stable value will make the prediction results of the SVM model better. Because if it has a value that tends to be unstable, then the prediction results from SVM will be less good.

\begin{tabular}{ccc} 
& Table 5. Features and Accuracy & Combination Table \\
\hline & Feature Combination & Accuracy Average \\
\hline \multirow{4}{*}{ 1 Feature } & Amplitude & 0,70 \\
& Magnitude & 0,62 \\
& Phase & 0,70 \\
& Energy & 0,69 \\
& Amplitude/Magnitude & 0,71 \\
& Amplitude/Phase & 0,69 \\
& Amplitude/Energy & 0,66 \\
& Magnitude/Phase & 0,72 \\
3 Features & Magnitude/Energy & 0,67 \\
& Phase/Energy & 0,62 \\
& Amplitude/Magnitude/Phase & 0,68 \\
4 Features & Amplitude/Magnitude/Energy & 0,61 \\
& Amplitude/Phase/Energy & 0,72 \\
& Magnitude/Phase/Energy & 0,61 \\
& &
\end{tabular}

\subsection{Signal Pattern}

In the last stage, the aim is to get the shape of the respondent's signal pattern to get a label in the affected or unaffected condition, based on pre-determined parameters, namely using a combination of 2 magnitude \& phase features.

\subsubsection{Label Determination Criteria}

This sub-chapter will determine labeling criteria based on signal pattern parameters for affected and unaffected conditions. By using the feature range of the combination of magnitude and phase, a slice of the range between respondents will be searched to be used as a signal pattern parameter. Then for respondent features that do not intersect with other respondent features, the respondent feature will be used as an outlier. The results of this range will then be used as a parameter to determine the label for each respondent. After obtaining the label with the signal pattern method, we will seek the accuracy from the data with a combination of magnitude and phase features, magnitude only, or phase only. Determination of accuracy can be determined by how much accurate data is divided by all data without outliers. The results of the highest accuracy of these 3 feature comparisons (magnitude and phase, magnitude only, or phase only) will be used as a feature parameter for determining the pattern of affected and unaffected respondent signals.

\subsubsection{Respondent Feature Range}

Based on the results of the combination of 2 magnitude \& phase features in sessions 2 to 4 , the values for each respondent's magnitude \& phase features. After obtaining the value of each respondent's magnitude and phase features, we will search each respondent's feature range for unaffected and affected conditions. The results of the feature range of each respondent can be seen in Table 6.

(c) 2021 The Authors. Published by Universitas Muhammadiyah Malang

This is an open access article under the CC BY SA license. (https://creativecommons.org/licenses/by-sa/4.0/) 
Table 6. Featured Range of Each Respondent

\begin{tabular}{cccl}
\hline \multirow{2}{*}{ Respondents } & \multicolumn{2}{c}{ Feature Range Session 2 - } & \multirow{2}{*}{ Label } \\
\cline { 2 - 3 } & magnitude & phase & \\
\hline 1 & $781-1015$ & $1,56810-1,56924$ & 0 \\
2 & $750-1236$ & $1,56889-1,56992$ & 1 \\
3 & $1234-1512$ & $1,56895-1,56994$ & 1 \\
4 & $929-1334$ & $1,5680-1,56858$ & 1 \\
5 & $914-1468$ & $1,56899-1,56912$ & 0 \\
6 & $1383-1920$ & $1,56917-1,56986$ & 1 \\
7 & $1493-2248$ & $1,56927-1,56941$ & 0 \\
8 & $1319-1936$ & $1,56989-1,56995$ & 1 \\
9 & $1003-1436$ & $1,56818-1,56983$ & 1 \\
10 & $1199-1880$ & $1,56989-1,56992$ & 1 \\
11 & $1460-1699$ & $1,56826-1,56925$ & 0 \\
\hline
\end{tabular}

After obtaining the feature range of magnitude and phase from each respondent, we will search the feature range between respondents for unaffected and affected conditions. Using the slice method between respondents' features will get the feature range between respondents as a parameter for determining the affected label. For determining the unaffected label, we will use the feature range of comparison data or session 1 dataset, wherein in session 1 there is no stimulus for changes in light intensity. Then for determining the affected label, it is obtained from the slices of the affected condition magnitude feature: 1234 to 1334 , and the outlier is respondent 6 . Then the slice results for the affected condition phase feature are 1.56889 to 1.56986 , and the outliers are respondents 4,8 , and 10 . So for values outside the range of affected conditions, they will be labeled as unaffected condition values. The results of the data range for determining the unaffected and unaffected label can be seen in Table 7.

Table 7. Feature Range Between Respondents

\begin{tabular}{cccc}
\hline Dataset & Magnitude Value Range & Phase Value Range & Label \\
\hline Comparison Dataset & $752-1233$ & $1,56806-1,56894$ & 0 \\
$\begin{array}{c}\text { Feature } \\
\text { Combination }\end{array}$ & $1335-1869$ & & 0 \\
& $1234-1334$ & $1,56895-1,56983$ & 1 \\
\hline
\end{tabular}

\subsubsection{Signal Pattern Results and Analysis}

Based on the results of the analysis of the data range of the combination of 2 magnitude \& phase features, it was found that there was a total of 15 accurate data and 15 inaccurate data. And also, for the total outliers, there are 12 data. The tested data will be accurate if it is in the feature combination data range for label 1 . Then the accuracy calculation is divided into 3 parts: magnitude \& phase, magnitude only, and phase only to get the best features like a signal pattern determination. Found that the average accuracy of each session for magnitude \& phase is 0.52 , for magnitude alone is 0.39 , and for phase-only is 0.67 . Based on the accuracy results, it indicates that the phase feature has the highest accuracy so that it becomes a feature parameter for determining the respondent's signal pattern for the affected condition. It is known that the value of the phase tends to be stable with a value between 1.56 to 1.57 , thus obtaining a larger slice than the magnitude, which has a less stable value. Then it is also known that the data pattern recognition method using a combination feature range is still less effective. Because the resulting range value still has a small range, to get accurate data from within that range, there is still little that can obtain. The values obtained tend to be less stable due to the influence of excessive movements of the respondents, such as scratching, holding the head, and moving a lot. Which causes a change in the high and low value obtained, which causes the value to become less stable. Then also, due to the lack of data and the method of determining the range parameters that may still be inaccurate, the accuracy obtained is less than optimal. For the accuracy of data from determining labels that are influenced by the combination of magnitude \& phase features in sessions 2 to 4 , it can be seen in Table 8 , which is information about brain signal patterns that are indicated as decision signals (the blue column shows the data is accurate or within the range of affected values) based on the magnitude and phase parameters.

Table 8. Data Pattern Accuracy Table

\begin{tabular}{ccccccc}
\hline \multirow{2}{*}{ Respondents } & \multicolumn{2}{c}{ Session 2 } & \multicolumn{2}{c}{ Session 3 } & \multicolumn{2}{c}{ Session 4 } \\
\cline { 2 - 7 } & Magnitude & Phase & Magnitude & Phase & Magnitude & Phase \\
\hline 2 & 1187 & 1,56939 & 750 & 1,56889 & 1236 & 1,56992 \\
3 & 1277 & 1,56895 & 1234 & 1,56994 & 1512 & 1,56986
\end{tabular}




\begin{tabular}{ccccccc}
4 & 929 & outlier & 1334 & outlier & 950 & outlier \\
6 & outlier & 1,56986 & outlier & 1,56917 & outlier & 1,56983 \\
8 & 1936 & outlier & 1925 & outlier & 1319 & outlier \\
9 & 1436 & 1,56882 & 1266 & 1,56983 & 1003 & 1,56818 \\
10 & 1880 & outlier & 1199 & outlier & 1320 & outlier \\
\hline \multirow{2}{*}{ Accuracy } & 0.16 & 0.75 & 0.5 & 0.75 & 0.5 & 0.5 \\
\cline { 2 - 8 } & \multicolumn{2}{c}{0.46} & \multicolumn{2}{c}{0.625} & & 0.5 \\
\hline
\end{tabular}

\section{Conclusion}

Can conclude that the condition is influenced and not affected by changes in light intensity in the signal pattern recognition process. The magnitude and phase feature ranges used are compared with the comparison data because the condition parameters are not affected. The magnitude and phase feature ranges for conditions outside this range are used as parameters for unaffected conditions. The signal system design process uses Fast Fourier Transform feature extraction to obtain a frequency response consisting of magnitude and phase. Another feature extraction is the extraction of energy signal amplitude and beta.

In the data collection process, only 4 respondents were not affected, and 7 respondents were affected. Respondents who were not affected were all male, and all affected were female. Based on the results of the questionnaire, respondents have specific color preferences. For respondents who are not affected have a choice for dark colors such as blue or black. Meanwhile, the affected respondents have a selection for bright colors such as light blue or pink. With increasing light intensity, color differences become more pronounced, making respondents interested in the resulting color differences and changing their choices. The accuracy of $67 \%$ for signal pattern recognition affected conditions with the range of phase features and $72 \%$ using SVM with RBF kernel as a feature classification method with a combination of magnitude and phase features. These results are sufficient to show that the intensity of dark and bright light can influence a person's decision to make an impulse purchase, and bright light tends to be more influential.

\section{References}

[1] A. Reghukumar, "Sense and Sensitivity in Architecture - The Use of Five Senses in Space making," Int. Res. J. Archit. Plan., vol. 4, no. 3, hal. 97-101, 2019.

[2] H. Zamani, A. Abas, dan M. K. MAmin, "Eye tracking application on emotion analysis for marketing strategy," J. Telecommun. Electron. Comput. Eng., vol. 8, no. 11, hal. 87-91, 2016.

[3] J. L. Burton, J. Gollins, L. E. McNeely, dan D. M. Walls, "Revisiting the relationship between ad frequency and purchase intentions how affect and cognition mediate outcomes at different levels of advertising frequency," J. Advert. Res., vol. 59, no. 1, hal. 27-39, 2019. https://doi.org/10.2501/JAR-2018-031

[4] B. Gonchigjav, "Results of neuromarketing study of visual attention and emotions of buyers in retail store environment," Proc. Mong. Acad. Sci., vol. 60, no. 01, hal. 52-64, 2020. https://doi.org/10.5564/pmas.v60i1.1337

[5] J. Saura, A. Reyes-Menendez, N. Matos, M. Correia, dan P. Palos-Sanche, "Consumer Behavior in the Digital Age," J. Spat. Organ. Dyn., vol. 8, no. 3, hal. 190-196, 2020.

[6] D. Khurniawan, M. Dimyati, dan D. Wulandari, "Influence of Sensory Branding Elements On Consumer Decision-Making Behavior In Buying Aqua With Neuromarketing Approach In Jember Regency," e-Journal Ekon. Bisnis dan Akunt., vol. 4 , no. 1, hal. $44,2017$. https://doi.org/10.19184/ejeba.v4i1.4572

[7] P. Widyastuti, "Does visual merchandising, store atmosphere and private label product influence impulse buying? Evidence in Jakarta," J. Bus. Retail Manag. Res., vol. 12, no. 3, hal. 140-148, 2018. https://doi.org/10.24052/JBRMR/V12IS03/ART-12

[8] L. Sun, J. Liang, Z. Liu, dan Y. Zhang, "Research on the Atmosphere and Emotionality of Apparel Stores Under LED Lighting Environment," in Lecture Notes in Electrical Engineering, 2019, vol. 543, hal. 44-49. http://dx.doi.org/10.1007/978-981-13-3663-8_7

[9] L. Alvino, E. Constantinides, dan M. Franco, "Towards a Better Understanding of Consumer Behavior: Marginal Utility as a Parameter in Neuromarketing Research," Int. J. Mark. Stud., vol. 10, no. 1, hal. 90, 2018. https://doi.org/10.5539/ijms.v10n1p90

[10] N. Kalkova, O. Yarosh, E. Mitina, dan V. Khokhlov, "Asymmetry of Visual Perception When Choosing Products: Methods and Algorithms of Neuromarketing," Int. J. Innov. Technol. Explor. Eng., vol. 9, no. 8, hal. 179-187, 2020. https://doi.org/10.35940/ijitee.H6256.069820

[11] B. Glova dan I. Mudryk, "Application of deep learning in neuromarketing studies of the effects of unconscious reactions on consumer behavior," Proc. 2020 IEEE 3rd Int. Conf. Data Stream Min. Process. DSMP 2020, hal. 337-340, 2020. https://doi.org/10.1109/DSMP47368.2020.9204192

[12] A. A. Mansor dan S. M. Isa, "Fundamentals of neuromarketing: What is it all about?," Neurosci. Res. Notes, vol. 3, no. 4, hal. 22-28, 2020. https://doi.org/10.31117/neuroscirn.v3i4.58

[13] D. Approach, M. Nilashi, E. Yadegaridehkordi, S. Samad, dan A. Mardani, "Decision to Adopt Neuromarketing Techniques for Sustainable Product Marketing: A Fuzzy Decision-Making Approach," 2020. https://doi.org/10.3390/sym12020305

[14] K. Bočková, J. Škrabánková, dan M. Hanák, "Theory and practice of neuromarketing: Analyzing human behavior in relation to markets," Emerg. Sci. J., vol. 5, no. 1, hal. 44-56, 2021. https://doi.org/10.28991/esj-2021-01256

[15] R. Indrawan, E. C. Djamal, dan R. Ilyas, "Neuropsychological Identification of Video Ads In Real-Time Using Fast Fourier Transform and Support Vector Machine," Semin. Nas. Apl. Teknol. Inf., hal. 6-10, 2017.

[16] I. Wijayanto, "Identification Of Electroencephalogram (EEG) Signal Conditions Exposed To $1800 \mathrm{Mhz} 4 \mathrm{~g}$ Lte Device Signal Radiation Using Learning Vector Quantization (LVQ)," TEKTRIKA - J. Penelit. dan Pengemb. Telekomun. Kendali, Komputer, Elektr. dan Elektron., vol. 1, no. 2, hal. 138-143, 2019. https://doi.org/10.25124/tektrika.v1i2.1746

[17] I. Lusiawati, "Brain development and optimization of human resources," Tedc, vol. 11, no. 2, hal. $162-171,2017$.

[18] J. Pratama, E. C. Djamal, F. Renaldi, dan U. Jenderal Achmad Yani JI Terusan Sudirman, "Identification of Product Attention Level Based on EEG Signals as Neuro Marketing," Semin. Nas. Apl. Teknol. Inf., no. August, hal. 2016, 2016.

[19] G. R. Iyer, M. Blut, S. H. Xiao, dan D. Grewal, "Impulse buying: a meta-analytic review," hal. 384-404, 2020. https://doi.org/10.1007/s11747019-00670-w

(C) 2021 The Authors. Published by Universitas Muhammadiyah Malang

This is an open access article under the CC BY SA license. (https://creativecommons.org/licenses/by-sa/4.0/) 
[20] H. S. Azman, M. K. M. Amin, dan S. Wibirama, "Exploring the subconscious decision making in neuromarketing research using eye tracking technique," J. Adv. Manuf. Technol., vol. 13, no. Special Issue 2, hal. 35-44, 2019.

[21] G. Plonka, D. Potts, G. Steidl, dan M. Tasche, Numerical Fourier Analysis. 2018.

[22] Z. Wei, C. Wu, X. Wang, A. Supratak, P. Wang, dan Y. Guo, "Using support vector machine on EEG for advertisement impact assessment," Front. Neurosci., vol. 12, no. MAR, 2018. https://doi.org/10.3389/fnins.2018.00076

[23] J. Zamani dan A. B. Naieni, "Best Feature Extraction and Classification Algorithms for EEG Signals in.pdf," vol. 7, no. 3, hal. 186-191, 2020. https://doi.org/10.18502/fbt.v7i3.4621

[24] K. Gibert, M. Sànchez-Marrè, dan J. Izquierdo, "A survey on pre-processing techniques: Relevant issues in the context of environmental data mining," Al Commun., vol. 29, no. 6, hal. 627-663, 2016. https://doi.org/10.3233/AlC-160710

[25] B. Richhariya dan M. Tanveer, "EEG signal classification using universum support vector machine," Expert Syst. Appl., vol. 106, hal. 169-182, 2018. https://doi.org/10.1016/j.eswa.2018.03.053 
